\title{
PSYCHOLOGICAL EMPOWERMENT AND DEVELOPMENT
}

\author{
Oladipo, S.E. PhD \\ Dept. of Counselling Psychology, Tai Solarin University of Education, \\ Ijagun, Ogun State.
}

\begin{abstract}
Using the archival method of investigation, this paper explores the subject of psychological empowerment (particularly in relation to youths) and national development. The specific objective of the paper is to explore and establish the importance of psychological empowerment of the masses and particularly the youths, in order to enhance national development. The paper establishes the fact that several empowerment programs that have been introduced at different times, by different regimes might not have yielded the expected results probably because attention has not been paid to the psychological empowerment of the masses. The assertion and recommendation that psychological empowerment is paramount to national development is based on the fact that human beings are psychological entities and as long as they experience psychological frustration, they may almost always antagonize government's move towards development. The paper thus concludes that psychological empowerment of the masses (particularly the youths) is of paramount importance in enhancing national development.
\end{abstract}

\section{Introduction}

What is empowerment?

Over the last decade, the concept of empowerment has emerged as the main paradigm of development throughout different governmental sectors (Zens, 2007). A review of definitions of empowerment reveals both diversity and commonality. Most definitions focus on issues of gaining power and control over decisions and resources that determine the quality of one's life, while some others also take into account; structural inequalities that affect entire social groups rather than focus only on individual characteristics.

The term empowerment has different meanings in different sociocultural and political contexts, and does not translate easily into all languages. My observation and exploration of local terms associated with empowerment around the world is that it has always led to lively discussions. These terms include self-strength, control, self-power, selfreliance, own choice, life of dignity in accordance with one's values, capable of fighting for one's rights, independence, own decision making, being free, awakening, and capability - to mention only a few. These 
definitions are embedded in local value and belief systems. Empowerment is of intrinsic value; as well as having instrumental value; relevant at the individual and collective level, and can be economic, social, or political. The term can be used to characterize relations within households or between people and other actors at the global level.

'Empowerment' is a term that has been embraced by a diverse range of institutions, from the World Bank to many more radical NGOs, but few of these share common definitions, while others like UNDP and Save the Children leave the term undefined (Scrutton and Luttrell, 2007). In other words, there is no clear centralized definition of the word.

\section{Purpose of study}

The specific objective of this paper is to explore and establish the importance of psychological empowerment of the masses and particularly the youths, in the enhancement of national development.

The paper aims at establishing the fact that because there is an experience of frustration aggression, there is a change in value orientation which has led to serious psychological disequilibrium which must be attended to through psychological empowerment in order to enhance national development.

\section{Some Definitions of Empowerment}

Rappaport, (1987) defined empowerment as a process by which people, organizations, and communities gain mastery over issues which are of concern to them.

The Oxford English Dictionary (1998) on the other hand, explains empowerment as: "giving (someone) the authority or power to do something". Power, in turn, is given for a purpose: to enable action.

The Swiss agency for Development and Cooperation defined empowerment as a process of emancipation in which the disadvantaged are empowered to exercise their rights, to obtain access to resources and to participate actively in the process of shaping society and making decisions. The activities of SDC are designed to strengthen the poor in bolstering their self-esteem, identity, self-confidence and ability to analyse problems and develop potential solutions of their own (SDC, 2004)

Consequently, in its broadest sense, empowerment is the expansion of freedom of choice and action; it involves increasing one's authority and control over the resources and decisions that affect one's life. As people exercise real choice, they gain increased control over their lives. It can also be defined as the act of enabling people to act on their own in order to reach their self-defined goals (Zimmerman, 1995). It 
needs be mentioned here that; empowerment could be in different facets, ranging from economic, political, social to psychological.

\section{What Is Psychological Empowerment?}

The focus of this paper is on Psychological Empowerment (PE). PE has been operationalised as an individual's cognitive state characterized by a sense of perceived control, competence, and goal internalization. PE is thus considered as a multi-faceted construct reflecting the different dimensions of being psychologically enabled, and is conceived of as a positive integrate of perceptions of personal control, a proactive approach to life, and a critical understanding of the socio-political environment, which is rooted firmly in a social action framework that includes community change, capacity building, and collectivity.

Empowerment has been perceived by researchers as aiming at achieving the following:

1. Developing the ability to access and control material and nonmaterial resources and to effectively mobilize them in order to influence decision outcomes.

2. Developing the ability to access and influence decisionmaking processes on various levels (household, community, national, global) in order to ensure the proper representation of one's interests (also described as getting a "voice"). (This usually requires the formation of local organizations to facilitate collective action)

3. Gaining an awareness of dominant ideologies and of the nature of domination that one is subjected to in order to discover one's identity, and ultimately to develop the ability to independently determine one's preferences and act upon them.

4. Developing the ability to trust in one's personal abilities in order to act with confidence.

Despite the aims and expectation about different empowerment programs, the reality however, has been that; real empowerment is yet to be achieved. This inability to achieve the desired goals may be owing to the lack of the psychological empowerment of the masses (particularly the youths) and an attempt at solving this problem has necessitated a discussion of this nature; on Psychological empowerment. 


\section{Why Psychological Empowerment?}

- There have been different economic and social empowerment programs that have failed to yield the expected results, most probably because the psychological make up of the people who are being empowered has not been put into consideration.

- Human beings are psychological entities and must be considered as such in the formulation of policies that are directly or indirectly related to them. Failure to do this may yield a negative result.

- Without psychological empowerment, wrong attitudes and behaviours may be exhibited by the masses which may eventually hamper good government policies.

- Development will be enhanced, since majority will see the need for patriotism and commitment to national development.

\section{Psychologically Empowerment Process}

It needs be pointed out that the achievement of economic and or social empowerment of the masses may not be possible without the psychological empowerment. When people are psychologically empowered, there will be a change in attitude, cognition and behaviour, which most assuredly will lead to a positive change in value orientation, increased patriotic actions, ability to postpone gratification of ones desires, improved Self-esteem, self-efficacy, self-consciousness as well as better psychological well-being which will culminate in a peaceful and developing society.

To achieve the above virtues therefore, the following psychological empowerment process is suggested.

\section{Psychological Empowerment Model}

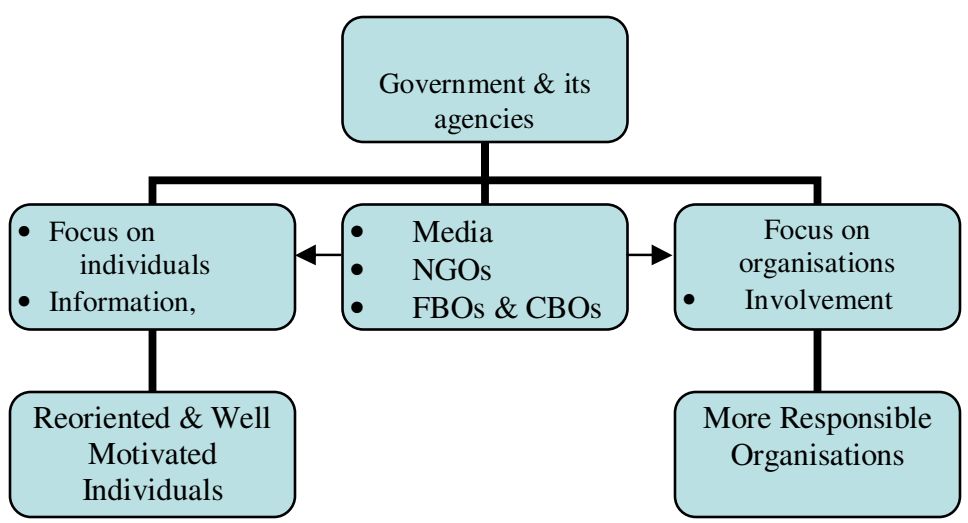

Source: Oladipo, 2008 
The PE model as shown above implies that:

The government should focus on the people; using the different media (Print, Audio, Audio-visual etc), Non-Governmental Organisations (NGOs), Faith-Based Organisations (FBOs) as well as Community Based Organisations (CBOs) to give the right orientation to the people. The masses are the kingpin (the most important person in a group or undertaking) and not the people in government, hence they should be involved in decision making, particularly on issues that bother on development program for them.

The average citizen has the notion that, those in government are there to siphon government money; hence he looks out for every opportunity to get his own. His sense of patriotism is eroded. The present situation of things as it is observable in Nigeria is that many people have the believe that except one goes through the crooked means he may not be able to succeed or prosper in Nigeria; and this most probably has affected most people's sense of value and right judgment negatively. When development programs and projects are executed without proper briefing and involvement of the people, there is most likely going to be failure, because the people might not see the need to support such a program, hence they can put up a nonchalant attitude that eventually leads to a collapse of such programs.

Report of researches in some foreign countries in the area of empowerment has shown that state reform that supports investments in people and their organizations leads to improved development outcomes, including improved governance, better- functioning and more inclusive services, more equitable access to markets, strengthened civil society and poor people's organizations, and increased assets and freedom of choice (Koerner,1993).

Institutional reform to support empowerment of people means changing the relationship between the state, the people and their organizations. It focuses on investing in people's assets and capabilities, both individual capabilities and the collective capacity to organize, to enable them to participate effectively in society and to interact with their governments, so as to strengthen the demand side of governance. State reform, whether at the national, state, or local government level, must focus on laws, rules, institutional mechanisms, values, and behavior that support and or facilitate the empowerment of the people. Changes in formal rules and regulations must be connected to efforts to enable people and other citizens to interact effectively with their governments and monitor governance. 
The focus of reform is thus on (a) designing mechanisms to support people's access to information, inclusion, and participation; (b) creating social accountability mechanisms; and (c) investing in people's organizational capacity to solve problems. Direct participation of people and their representatives is not feasible or realistic in every context. Civil society intermediaries such as research institutes, NGOs, and faith-based organizations have important roles to play in carrying people's voices to local and national decision makers.

The kind of state reform that is feasible and relevant is conditioned by the country's social and political structures at a particular point in time. Over time, there are feedback loops that affect social and political structures, which then leads to changes in the state mechanisms for supporting empowerment. For example, as the importance of access to information becomes apparent, countries may execute new freedom of information acts and invest in information technology to ease public access to information.

When people are thus empowered, they are better off in the sense that they have better self-efficacy (because they will believe more in themselves and their ability, improved self-esteem (because they now see themselves as participating in governance); they are now rightly motivated and well adjusted with the possibility of high life satisfaction since there is a positive change in their value orientation which may result in more pro-social behavior. This is actually summarized in Maslow's Hierarchy of needs.

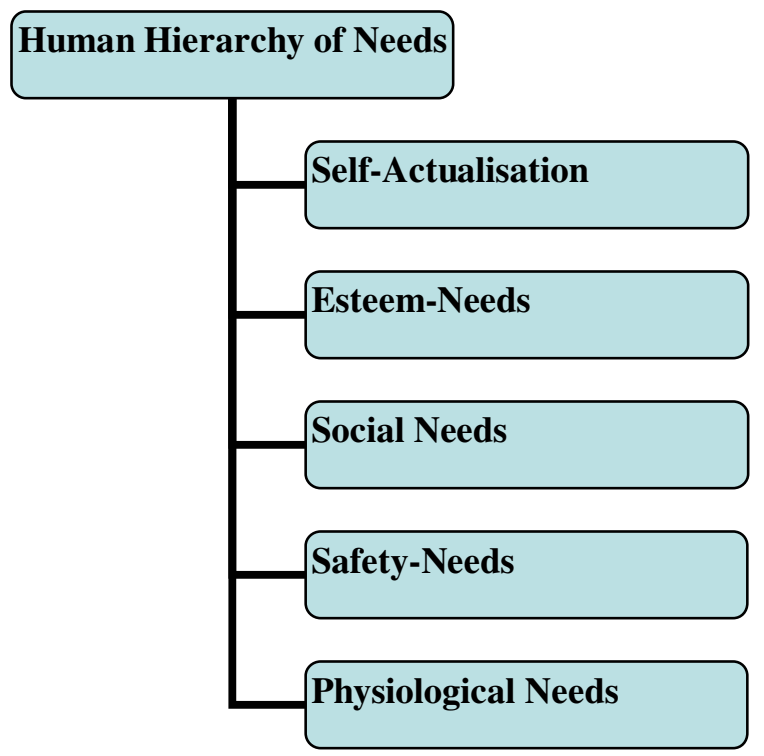


The basis of Maslow's theory is that human beings are motivated by unsatisfied needs, and that certain lower needs need to be satisfied before higher needs can be satisfied. Maslow, position is that there are general needs (physiological, safety, love, and esteem) which have to be fulfilled before a person is able to act unselfishly. These needs were dubbed "deficiency needs." While a person is motivated to fulfil these basal desires, they continue to move toward growth, and eventually selfactualization. The satisfaction of needs is quite healthy, while preventing their gratification most often than not will make people ill or engage an anti-social behaviour.

As a result, for adequate motivation of the masses, it is important that leaders understand which needs are active for the people they govern. In this regard, Abraham Maslow's model indicates that basic, low-level needs such as physiological requirements and safety must be satisfied before higher-level needs such as self-fulfilment are pursued. As depicted in hierarchical diagram above, sometimes called 'Maslow's Needs Pyramid', when a need is satisfied it no longer motivates and the next higher need takes its place.

\section{Implications of need hierarchy for empowerment}

If Maslow's theory holds, there are some important leadership implications to enhance people's motivation and eventual empowerment.

- Physiological Needs: are the basic needs of feeding, accommodation, salaries/wages that are perceived by the employees to be sufficient for the purchase of the essentials of life.

- Safety Needs: are needs to for a safe environment to live in, freedom from threats, and relative security.

- Social Needs: Create a feeling of acceptance, belonging, and community by reinforcing team dynamics.

- Esteem Needs: Recognize achievements, assign important projects, and provide status to make people feel appreciated and valued.

- Self-Actualization: Provide challenging and meaningful work which enables innovation, creativity, and progress according to long-term goals.

However, not all people are driven by the same needs - at any time different people in different social strata may be motivated by entirely different factors. It is important therefore to understand the needs of each set of people in different 
communities in order to be able to meet their peculiar needs and motivate them to commitment and more patriotic acts.

\section{Conclusion}

It is expedient to conclude that attainment of economic or social of empowerment in any community, state or nation depends strongly on the extent to which the masses are psychologically empowered. They masses are the kingpin (the most important person in a group or undertaking), hence the need to give them the necessary motivation so as to see the government as 'our' government and not 'their' government.

\section{References}

Koerner, M.M., (1993). Consequences of empowerment: The impact of perceived empowerment on turnover propensity, motivation to exert extra effort, and use of influence strategies. A Paper presented at the 1993 National Academy of Management Meetings, Atlanta, Georgia.

Rappaport, J. (1987). Terms of empowerment/exemplars of prevention: Toward a theory for Community Psychology. American Journal of Community Psychology. 15(2):121-148.

Sanjay, M.T. (1999) Psychological Empowerment: Definition, Measurement, and Validation Canadian Journal of Behavioural Science, http://findarticles.com/p/articles/mi_qa3717/is_199907/ai_n88 69161/pg_2?tag=artBody;col1

Scrutton, C. and Luttrell, C. (2007) The definition and operationalisation of empowerment in different development agencies. Curled from the internet on 23/9/08, Poverty-wellbeing.net.

SDC (2004) Creating the Prospect of Living a Life in Dignity - Principles

Guiding the SDC in its Commitment to Fighting Poverty, Berne: SDC.

Curled from the internet on 23/9/08

http://www.digitalhimalaya.com/collections/journals/opsa/pdf LOPSA_08_10.pdf.

Zenz, A. (2007) Evaluating Empowerment: The World Vision Area Development Programme. Curled from the internet on 23/9/08 http://www.digitalhimalaya.com/collections/journals/opsa/pdf LOPSA_08_10.pdf

Zimmerman, M. A (1995) Psychological empowerment: Issues and illustrations. American Journal of Community Psychology. 25(5):581599. 